\title{
Reduced virulence of Candida albicans mutants lacking the GNA1 gene encoding glucosamine-6-phosphate acetyltransferase
}

\author{
Toshiyuki Mio, Michiko Kokado, Mikio Arisawa \\ and Hisafumi Yamada-Okabe
}

\author{
Author for correspondence: Toshiyuki Mio. Tel: +81 46747 2242. Fax: +81 467465320. \\ e-mail: toshiyuki.mio@roche.com
}

Department of Mycology, Nippon Roche Research Center, 200 Kajiwara, Kamakura, Kanagawa 247-8530, Japan

\begin{abstract}
The yeast GNA1 gene encodes glucosamine-6-phosphate acetyltransferase which catalyses the reaction of glucosamine 6-phosphate with acetyl-CoA to form $\mathbf{N}$-acetylglucosamine 6-phosphate, a fundamental precursor in UDP- $\mathbf{N}$ acetylglucosamine biosynthesis. Candida albicans mutants lacking GNA1 were viable in the presence of $\boldsymbol{N}$-acetylglucosamine. To confirm the physiological importance of C. albicans GNA1, the virulence of a C. albicans gna1 $\Delta$ null mutant was examined in a mouse model of candidiasis. When injected intravenously into mice, the virulence of the $C$. albicans gna1 $1 \Delta$ null mutant was significantly attenuated. The reduced virulence appeared to be the result of rapid clearance from host tissue. These data suggest that $C$. albicans GNA1 is required for survival of the fungus in host animals, probably because an insufficient level of $\boldsymbol{N}$-acetylglucosamine is available from the host tissues.
\end{abstract}

Keywords: GNA1, glucosamine-6-phosphate acetyltransferase, antifungal target, Candida albicans, virulence

\section{INTRODUCTION}

Candida albicans is an important pathogen causing deep mycosis in immunocompromised patients (Odds, 1987). In addition, C. albicans cells undergo morphological conversion between yeast and hyphal forms (Gow \& Gooday, 1987; Shepherd, 1985). The ability to form hyphae seems to play a role in virulence (Odds, 1994).

UDP-N-acetylglucosamine (UDP-GlcNAc) is an essential precursor of peptidoglycan and lipid A in bacteria (Holtje \& Schwarz, 1985; Park, 1987; Raetz, 1987), and of chitin and glycoproteins in yeast (Cabib et al., 1982; Herscovics \& Orlean, 1993). In the yeast Saccharomyces cerevisiae, four enzymes are involved in the reaction from fructose 6-phosphate to UDPGlcNAc: (i) glutamine:fructose-6-phosphate amidotransferase (Watzele \& Tanner, 1989; Smith et al., 1996); (ii) glucosamine-6-phosphate acetyltransferase (Mio et al., 1999); (iii) phosphoacetylglucosamine mutase (Hofmann et al., 1994); and (iv) UDP-GlcNAc pyrophosphorylase (Mio et al., 1998). The gene for glutamine:fructose-6-phosphate amidotransferase has

Abbreviations: GalNAc, $\mathrm{N}$-acetylgalactosamine; GICNAc, $\mathrm{N}$-acetylglucosamine; ManNAc, $N$-acetylmannosamine. been cloned by complementing the gcn 1 mutation, and its expression is increased several fold by $\alpha$-factor (Whelan \& Ballou, 1975; Watzele \& Tanner, 1989). AGM1, which suppresses the growth defect caused by a pgm1 pgm2 double mutation, is a phosphoacetylglucosamine mutase gene (Boles et al., 1994; Hofmann et al., 1994). In previous papers, we reported that UAP1 and GNA1 genes encode UDP-GlcNAc pyrophosphorylase and glucosamine-6-phosphate acetyltransferase, respectively (Mio et al., 1998, 1999). The genes for UDP-GlcNAc biosynthesis are conserved between $S$. cerevisiae and C. albicans. In addition, disruption of each of the S. cerevisiae genes GFA1 (Watzele \& Tanner, 1989), GNA1, AGM1 and UAP1 was lethal, suggesting that enzymes involved in UDP-GlcNAc biosynthesis are potential targets for antifungal agents.

On the other hand, a GlcNAc catabolic pathway has been reported in C. albicans. GlcNAc can be transported into the cells by GlcNAc permease and converted to fructose 6-phosphate by the sequential action of GlcNAc kinase, GlcNAc-6-phosphate deacetylase and glucosamine-6-phosphate deaminase (Singh \& Datta, 1979; Gopal et al., 1982; Datta et al., 1989). Therefore, C. albicans gna1 null mutants should grow in the presence of GlcNAc. In this work, we obtained C. albicans heterozygous and homozygous gna1s null mutants and 
characterized their phenotypes. In addition, we show the effect of a mutation in GNA1 on virulence in a mouse model of candidiasis.

\section{METHODS}

C. albicans strains. The C. albicans strains used in this study are listed in Table 1.

Disruption of the C. albicans GNA1 gene. Gene disruption was carried out according to the ura blaster protocol (Alani et al., 1987). To disrupt the C. albicans GNA1 gene, pGNA1 was constructed by cloning the 450 bp BamHI-SmaI fragment of C. albicans GNA1 into pUC19 (Fig. 1a). After digestion of pGNA1 with EcoT22I, the resulting DNA fragment was ligated with a $3.8 \mathrm{~kb}$ Bam $\mathrm{HI}-B g l \mathrm{II}$ fragment carrying the his G-URA3-his G cassette to generate pGNA1U. Thus, his $G-$ URA3-his G was inserted into the EcoT22I site of C. albicans GNA1. After pGNA1U had been linearized by digestion with $B a m$ HI and SmaI, $100 \mu \mathrm{g}$ of the DNA was transfected into C. albicans CAI4 cells by the lithium acetate method (Ito et al., 1983), and CGM1 was obtained as a single GNA1 allelic disruption by selection of $\mathrm{Ura}^{+}$transformants. Before the second round of transformation, the URA3 gene that had been integrated into the C. albicans genome was excised by 5fluoroorotic acid (Lundblad, 1992). CGM120 was isolated as a gna1 $\Delta$ null mutant after the second round of transformation with the same cassette. The C. albicans URA3 gene was obtained by functional complementation. YPH499 (MATa ura3 lys2 ade2 trp1 his3 leu2) was transformed with a $C$. albicans genomic library (Yamada-Okabe et al., 1996) and uracil prototrophs were selected on - ura plates. pCaURA3 was constructed by cloning the $3.3 \mathrm{~kb}$ Sty $\mathrm{I}-P$ st $\mathrm{I}$ fragment containing the entire C. albicans URA3 into pUC18. After digestion of pCaURA 3 with PstI and SmaI, the resulting DNA fragment was transformed into CGM12 and CGM120 to integrate it into the $u$ ra $3 \Delta:: i m m 434$ locus. All C. albicans cells were cultured in YPDGlcNAc medium ( $2 \%$ peptone, $1 \%$ yeast extract, $2 \%$ glucose and $2 \%$ GlcNAc) at $30{ }^{\circ} \mathrm{C}$.

Southern blot analysis. Genomic DNA was prepared as described by Kasahara et al. (1994). Twenty-five micrograms of genomic DNA that had been digested with NspV was fractionated by agarose gel electrophoresis, transferred to Nylon membranes and hybridized with the 163 bp SmaI-NdeI fragment of C. albicans GNA1. Hybridization was carried out under stringent conditions in a buffer containing $50 \mathrm{mM}$ sodium phosphate $(\mathrm{pH} 6.5), 5 \times$ SSC, $5 \times$ Denhardt's solution, $50 \%(\mathrm{v} / \mathrm{v})$ formamide, $0.25 \mathrm{mg}^{\circ}$ salmon sperm DNA ml $\mathrm{m}^{-1}$ and $0 \cdot 1 \%(\mathrm{w} / \mathrm{v})$ SDS at $42{ }^{\circ} \mathrm{C}$ for $18 \mathrm{~h}$.

Assay for glucosamine-6-phosphate acetyltransferase (EC 2.3. 1 . 4). Glucosamine-6-phosphate acetyltransferase activity was determined by measurement of CoA produced. Since CoA reacts with 2-nitrobenzoic acid and releases 4-nitrothiophenolate (Gehring et al., 1996; Riddles et al., 1983), an assay was performed in a $50 \mu \mathrm{l}$ reaction mixture containing $50 \mathrm{mM}$ Tris $/ \mathrm{HCl}(\mathrm{pH} 7 \cdot 5), 5 \mathrm{mM} \mathrm{MgCl}_{2}, 150 \mu \mathrm{M}$ glucosamine 6phosphate, $150 \mu \mathrm{M}$ acetyl-CoA, $10 \%$ (v/v) glycerol and $70 \mu \mathrm{g}$ of crude extract obtained from the mutants. After incubation at $37^{\circ} \mathrm{C}$ for $20 \mathrm{~min}$, the reaction was terminated by adding a solution containing $50 \mathrm{mM}$ Tris $/ \mathrm{HCl}(\mathrm{pH} 7.5)$ and $6.4 \mathrm{M}$ guanidine hydrochloride, and then $50 \mu \mathrm{l}$ of a solution containing $50 \mathrm{mM}$ Tris $/ \mathrm{HCl}(\mathrm{pH} 7 \cdot 5), 1 \mathrm{mM}$ EDTA and $20 \mu \mathrm{M}$ 2 -nitrobenzoic acid. The amount of CoA produced by glucosamine-6-phosphate acetyltransferase was estimated from that of 4-nitrothiophenolate by measuring the absorbance at $412 \mathrm{~nm}$.

Systemic infection of mice. Stationary-phase C. albicans cells were harvested from the YPDGlcNAc cultures. The cells were washed with sterile distilled water, suspended in saline and counted with a haemocytometer. Cell suspensions $(0.2 \mathrm{ml})$ containing $1 \times 10^{5}, 1 \times 10^{6}$ and $1 \times 10^{7}$ cells were then injected intravenously into mice. Each test strain was injected into five mice.

Quantification of C. albicans in infected tissue. Cell suspensions $(0 \cdot 2 \mathrm{ml})$ containing $1 \times 10^{5}, 1 \times 10^{6}$ and $1 \times 10^{7}$ cells were injected intravenously into mice. The number of $C$. albicans cells in the kidney and liver was examined $3 \mathrm{~d}$ after infection.

\section{RESULTS}

\section{Disruption of the C. albicans GNA1 gene}

S. cerevisiae GNA1 (ScGNA1) is an essential gene in this yeast. Furthermore, the addition of GlcNAc did not suppress the growth defect of ScGNA1-deficient cells (data not shown). Because $S$. cerevisiae does not carry

Table 1. C. albicans strains used in this study

\begin{tabular}{|c|c|c|c|}
\hline Strain & Parent & Genotype & Reference \\
\hline CAI4 & CAF2 & ura3s::imm434/ura3s::imm434 & Fonzi \& Irwin (1993) \\
\hline CGM1 & CAI4 & $\begin{array}{l}\text { ura3s::imm } 434 / \text { ura } 3 \Delta:: \text { imm } 434, \\
\text { GNA1/gna } 1 \Delta: \text { : hisG-URA3-hisG }\end{array}$ & This work \\
\hline CGM12 & CGM1 & $\begin{array}{l}\text { ura } 3 \Delta:: \text { imm } 434 / \text { ura } 3 \Delta:: \text { imm } 434 \\
\text { GNA1/gna } 1 \Delta: \text { : his } G\end{array}$ & This work \\
\hline CGM120 & CGM12 & $\begin{array}{l}\text { ura3s::imm 434/ura3s::imm434, } \\
\text { gna } 1 \Delta: \text { :hisG/gna } 1 \Delta:: \text { hisG-URA3-hisG }\end{array}$ & This work \\
\hline CGM1210 & CGM121 & $\begin{array}{l}\text { ura } 3 \Delta:: \text { imm } 434 / \text { ura } 3 \Delta:: \text { imm } 434 \\
\text { gna } 1 \Delta:: \text { his } G / \text { gna } 1 \Delta:: \text { his } G\end{array}$ & This work \\
\hline CAF2 & SC5314 & URA3/ura3s::imm434 & Fonzi \& Irwin (1993) \\
\hline CGM12-1 & CGM12 & URA3/ura3s::imm434, GNA1/gna1s::hisG & This work \\
\hline CGM1210-1 & CGM1210 & $\begin{array}{l}\text { URA3/ura3s ::imm } 434 \\
\text { gna } 1 \Delta: \text { : his } G / \text { gna } 1 \Delta:: \text { his } G\end{array}$ & This work \\
\hline
\end{tabular}


(a)

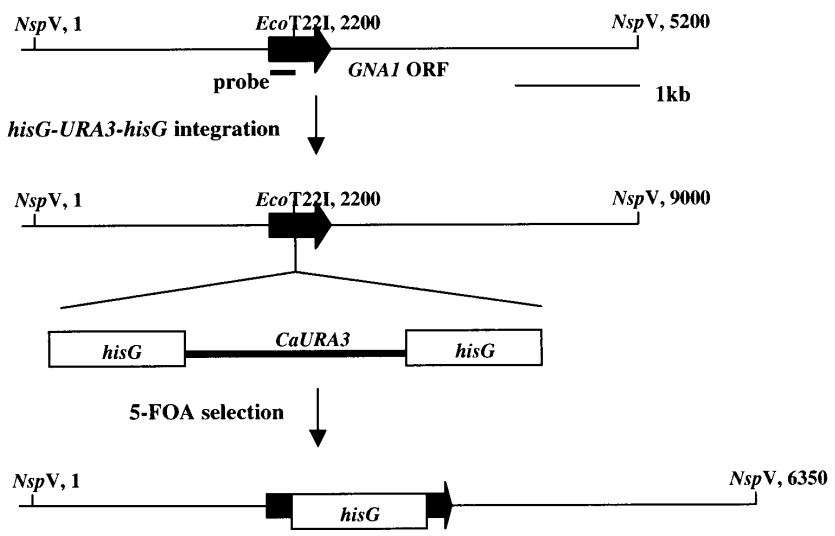

(b)

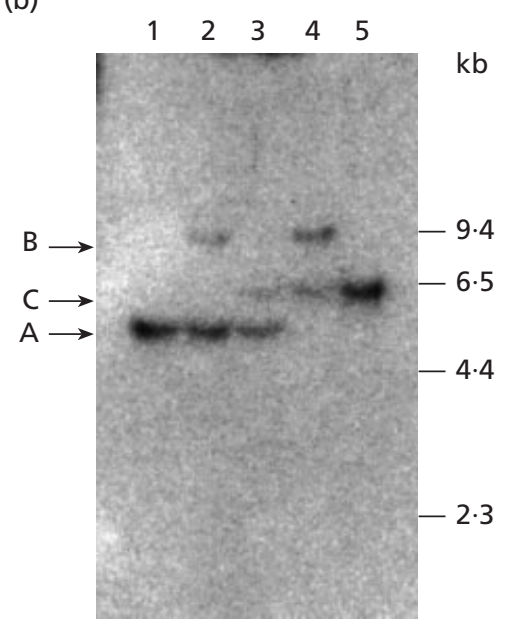

Fig. 1. Disruption of GNA1. (a) Strategy for disruption of GNA1 and the DNA used for the probe. Restriction endonuclease sites and nucleotide positions, which are counted from the NspV site present in the $5^{\prime}$ noncoding region of GNA1, are indicated. (b) Integration of his $G$ sequences into GNA1 alleles was confirmed by Southern blotting. Genomic DNA $(25 \mu \mathrm{g})$ that had been digested with NspV was fractionated by agarose gel electrophoresis, transferred to Nylon membranes and hybridized with the $163 \mathrm{bp}$ Smal-Ndel fragment of GNA1 as a probe. Bands derived from the GNA1 allele, the gna1 $1:$ hisGURA3-hisG allele and the gna1 $\triangle:$ :hisG allele are indicated by A, B and C, respectively. Lanes: 1, CAl4; 2, CGM1; 3, CGM12; 4, CGM120; 5, CGM1210.

the gene for GlcNAc kinase, UDP-GlcNAc is not synthesized in these cells. In contrast, the C. albicans gna1s null mutant should grow in the presence of GlcNAc because GlcNAc kinase exists in C. albicans. To test this hypothesis, transformants in the second round of disruption of the GNA1 locus were selected on plates supplemented with $2 \%$ GlcNAc. When 100 transformants were plated onto YPD, 8 out of 100 did not grow. The result of Southern blot analysis revealed that the hisG-URA3-hisG module was correctly integrated into the GNA1 locus and that URA3 was eliminated by 5 -fluoroorotic acid (Fig. 1b). Thus, a null mutation of gna1 in C. albicans is lethal in the absence of GlcNAc.

To examine the effect of GNA1 disruption on glucosamine-6-phosphate acetyltransferase, the activity of the enzyme from mutants was measured. When incubated with glucosamine 6-phosphate and acetylCoA, the crude extract from wild-type CAI4 produced $38.9 \pm 3.9 \mu \mathrm{M}$ CoA from acetyl-CoA. In contrast, the homozygous gna1 $\Delta$ null mutant (CGM1210-1) showed a large reduction in glucosamine-6-phosphate acetyltransferase activity $(2 \cdot 0 \pm 0 \cdot 4 \mu \mathrm{M}$ CoA released), and the activity of the heterozygous gna1s mutant (CGM12-1) retained about $40 \%$ of wild-type CAI4 activity $(14 \cdot 2 \pm 2 \cdot 9 \mu \mathrm{M}$ CoA released), indicating a gene dosage effect.

\section{Effect of GNA1 disruption on morphology and growth}

In $S$. cerevisiae, ScGNA1-deficient cells exhibited morphological defects: most of the yeast cells swelled and then often lysed (Mio et al., 1999). The role of GNA1 on C. albicans growth was investigated. CGM1210-1 grew and formed hyphae in YPD + GlcNAc (Fig. 2b), and the growth rate was indistinguishable from that of wildtype (CAF2) or CGM12-1 (the doubling times for CAF2, CGM12-1 and CGM1210-1 were 71, 64 and $73 \mathrm{~min}$, respectively) (Fig. 2a). When CGM1210-1 was cultured on YPD, most of the cells dramatically enlarged, swelled and became defective in cell separation (Fig. 2b). This phenotype was similar to that caused by depletion of ScGNA1, suggesting that C. albicans GNA1 is also essential for growth and the synthesis of UDP-GlcNAc.

Next, the ability of CGM1210 to grow on media containing other acetylhexosamines was assessed. CGM1210 grew on $\mathrm{N}$-acetylmannosamine (ManNAc) and $\mathrm{N}$-acetylgalactosamine (GalNAc) as carbon sources, but the growth was slower than that with GlcNAc (Fig. 3). The addition of glucose significantly decreased growth on ManNAc and GalNAc, whereas there was no effect on GlcNAc (Fig. 3). These data suggest that UDP-GlcNAc can be synthesized from GlcNAc, ManNAc or GalNAc, and that the catabolic pathways of both ManNAc and GalNAc are repressed by glucose. Next, we examined the growth of CGM1210 over a range of GlcNAc concentrations. CGM1210 failed to grow at a GlcNAc concentration less than $10 \mu \mathrm{M}$ (data not shown). In addition, $20 \%$ calf serum did not suppress the growth defect caused by the gna1 $\Delta$ mutation, indicating that the concentration of GlcNAc in calf serum is less than $10 \mu \mathrm{M}$.

\section{Effect of disruption of GNA1 on the virulence of C. albicans}

To investigate whether GNA1 was required for C. albicans infection, we examined the virulence of mutant strains in a mouse model of systemic candidiasis. All mice infected with $1 \times 10^{5}, 1 \times 10^{6}$ or $1 \times 10^{7}$ cells of CGM1210-1 survived (Fig. 4). In contrast, all mice infected with the parental strain CAF2 succumbed to the 
(a)
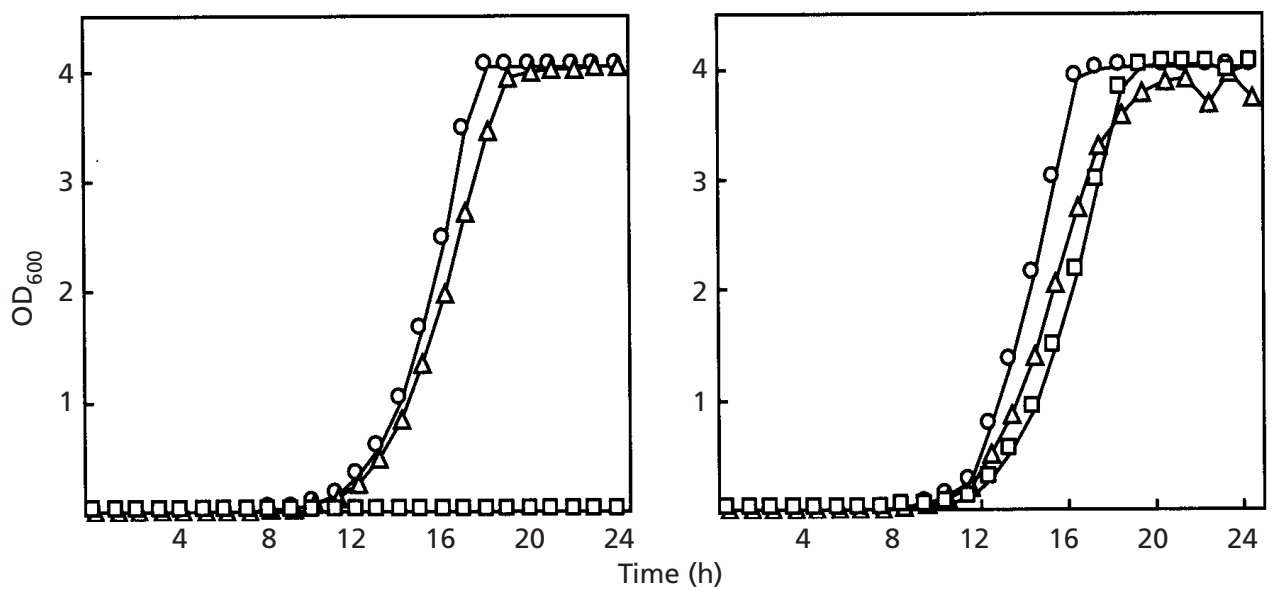

(b)
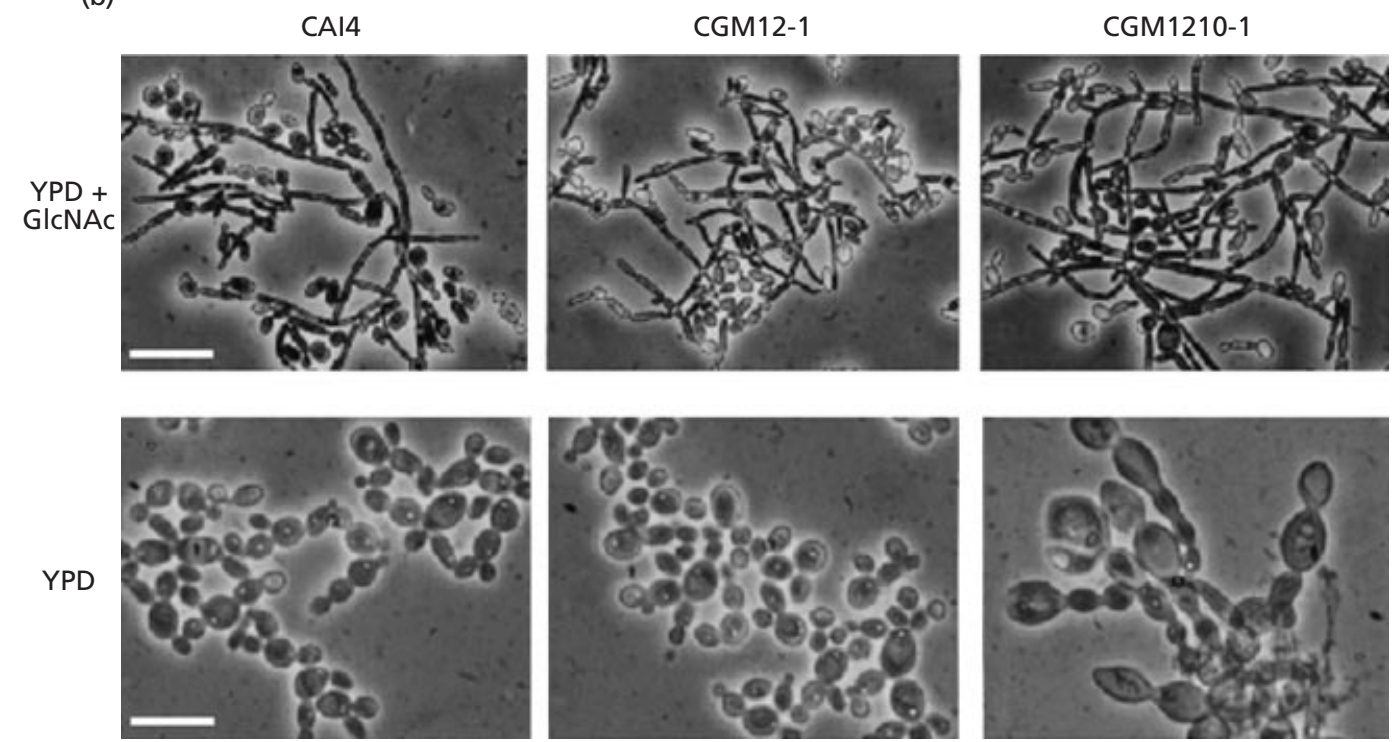

Fig. 2. Effects of disruption of GNA1 on growth and morphology. (a) Effects on growth of wild-type CAF2 (O), CGM12-1 $(\triangle)$ and CGM1210-1 $(\square)$. Cells of the indicated strains were cultured in YPD medium in the absence (left) or presence (right) of GICNAc and cell growth was monitored with a Biophotorecorder (Advantec). (b) Morphological change caused by the disruption of GNA1. C. albicans cells of CAF2, CGM12-1 and CGM1210-1 were cultured in YPD medium in the presence (upper panels) or absence (lower panels) of GICNAC and incubated at $30^{\circ} \mathrm{C}$. Photographs were taken after $18 \mathrm{~h}$. Bars, $40 \mu \mathrm{m}$ (upper panels), $20 \mu \mathrm{m}$ (lower panels).

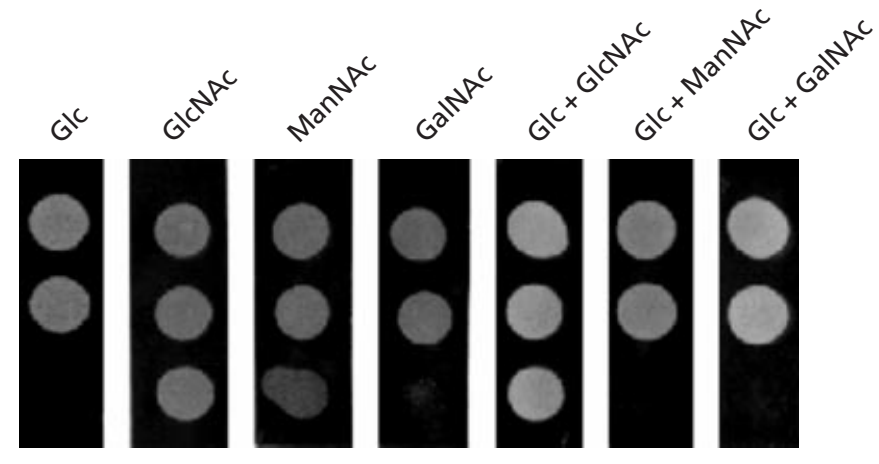

Fig. 3. Ability of gna1 $1 \Delta$ mutants to grow on acetylhexosamines. Cell suspensions $(5 \mu \mathrm{l})$ containing $1 \times 10^{5}$ cells of CAl4 (wild-type), CGM12 or CGM1210 were spotted on agar plates containing GIcNAc, ManNAc or GalNAc in the absence or presence of glucose (Glc) and incubated at $30^{\circ} \mathrm{C}$. Photographs were taken after $24 \mathrm{~h}$. 

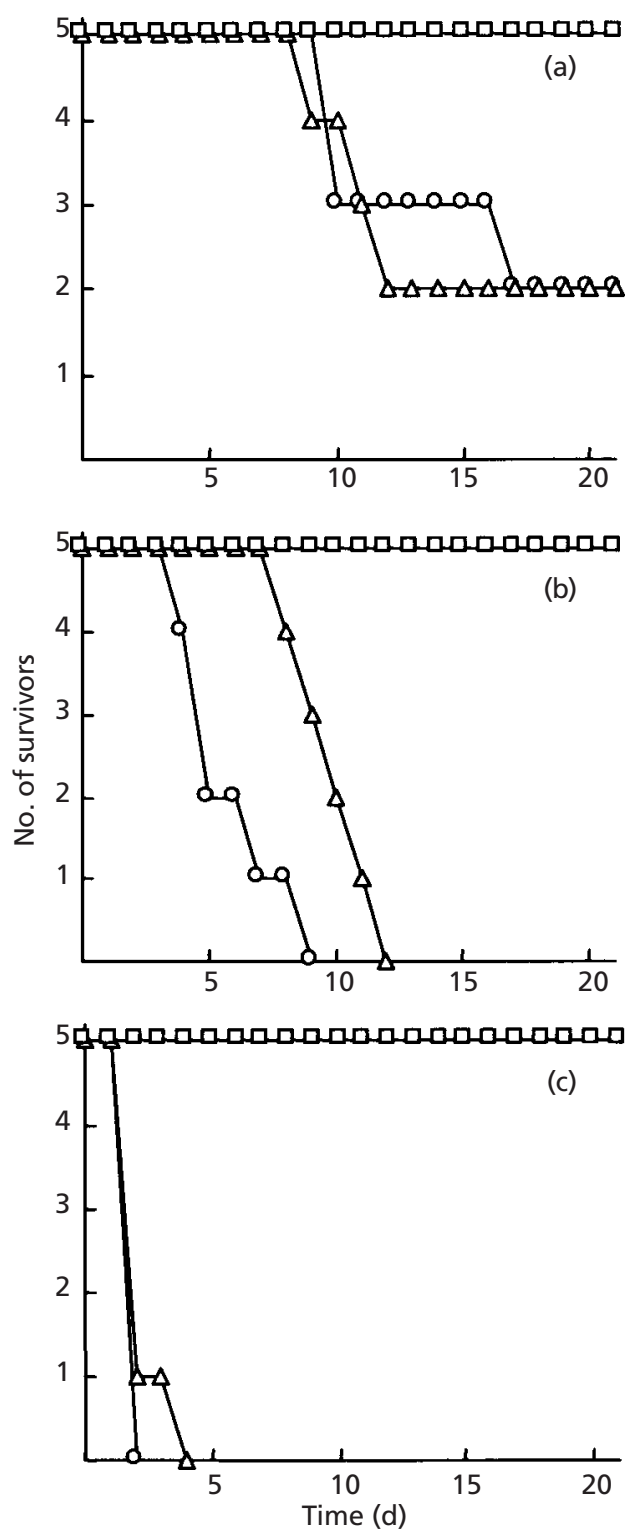

Fig. 4. Survival of mice following infection with $C$. albicans. Effects of the disruption of GNA1 on the virulence of CAF2 (wild-type; $O), C^{2}$ 12-1 $(\triangle)$ and CGM1210-1 ( $\square$ ). Saline $(0.2 \mathrm{ml})$ containing $1 \times 10^{5}(\mathrm{a}), 1 \times 10^{6}$ (b) or $1 \times 10^{7}$ (c) cells was injected intravenously into mice. Each test strain was injected into five mice.

infection within $2 \mathrm{~d}$, and the extent of mortality of CGM12-1 was half that of CAF2 (Fig. 4).

The number of C. albicans cells in host tissues infected with mutant strains was determined (Table 2). No cells were recovered from the mice infected with CGM12101, indicating that CGM1210-1 was rapidly cleared from the kidney and liver. In addition, the recovery of CGM12-1 was significantly lower than that of the wildtype, demonstrating that the virulence of mutant strains correlated with the level of glucosamine-6-phosphate
Table 2. Recovery of C. albicans from infected tissues

\begin{tabular}{|llcc|}
\hline Challenge dose & $\begin{array}{c}\text { C. albicans } \\
\text { strain }\end{array}$ & \multicolumn{2}{c|}{$\begin{array}{c}\log _{10} \text { C.f.u. per mouse } \\
\text { (mean } \pm \text { SD) }\end{array}$} \\
\cline { 3 - 4 } & & Kidney & Liver \\
\hline \multirow{2}{*}{$1 \times 10^{7}$} & & $6 \cdot 07 \pm 0 \cdot 09$ & $4 \cdot 21 \pm 0 \cdot 23$ \\
& CAF2 & $3 \cdot 94 \pm 0 \cdot 43$ & $3 \cdot 41 \pm 0 \cdot 27$ \\
& CGM12-1 & $0 \dagger$ & $1 \cdot 45 \pm 0 \cdot 21^{*}$ \\
& CGM1210-1 & $4 \cdot 29 \pm 0 \cdot 20$ & $2 \cdot 70 \pm 0 \cdot 16$ \\
& CAF2 & $2 \cdot 99 \pm 0 \cdot 55^{*}$ & $2 \cdot 38 \pm 0 \cdot 46$ \\
& CGM12-1 & $0 \dagger$ & $0 \dagger$ \\
& CGM1210-1 & $3 \cdot 01 \pm 0 \cdot 30$ & $1 \cdot 70 \pm 0 \cdot 17$ \\
& CAF2 & $2 \cdot 30 \pm 0 \cdot 01^{*}$ & $1 \cdot 78 \pm 0 \cdot 02^{*}$ \\
& CGM12-1 & $0 \dagger$ & $0 \dagger$ \\
\hline
\end{tabular}

*Some mice cleared infection.

† All mice cleared infection.

acetyltransferase activity (Table 2). These data suggest that GNA1 is essential for C. albicans virulence.

\section{DISCUSSION}

In this work, we investigated the physiological role of GNA1 through characterization of the phenotypes of $C$. albicans mutants. We found that the C. albicans gna $1 \Delta$ null mutant grew in the presence of GlcNAc, whereas ScGNA1-deficient $S$. cerevisiae cells did not. This indicates that GlcNAc is converted to UDP-GlcNAc by the sequential actions of GlcNAc kinase, phosphoGlcNAc mutase and UDP-GlcNAc pyrophosphorylase. ManNAc and GalNAc also suppressed the growth defect caused by the GNA1 disruption. GlcNAc kinase and ManNAc-2-epimerase activities have been reported in C. albicans (Biswas et al., 1979). These facts suggest that ManNAc and GalNAc are converted to GlcNAc by each respective epimerase.

The avirulence of the homozygous gna1s null mutant indicates that GNA1 is important for the virulence of $C$. albicans. In addition, the heterozygous gnas mutant displayed an intermediate virulence phenotype, suggesting that the reduced virulence of gna1s mutants is associated with the loss of glucosamine-6-phosphate acetyltransferase activity.

The homozygous gna1 $\Delta$ null mutant is not defective in growth rate and hyphal formation in the presence of enough GlcNAc. In addition, the calcofluor susceptibility of the mutants is similar to that of the wild-type, suggesting that the mutants synthesize chitin from exogenous GlcNAc in an amount sufficient for growth (data not shown). These facts suggest that the homozygous gnas null mutant does not survive in host animals because of an insufficient level of GlcNAc in the tissues. 


\section{ACKNOWLEDGEMENTS}

We thank S. B. Miwa for reading the manuscript and T. Takahashi for assisting with the experiments.

\section{REFERENCES}

Alani, E., Cao, L. \& Kleckner, N. (1987). A method for gene disruption that allows repeated use of URA3 selection in the construction of multiply disrupted yeast strains. Genetics 116, 541-545.

Biswas, M., Singh, B. \& Datta, A. (1979). Induction of Nacetylmannosamine catabolic pathway in yeast. Biochim Biophys Acta 585, 535-542.

Boles, E., Liebetrau, W., Hofmann, M. \& Zimmermann, F. K. (1994). A family of hexosephosphate mutases in Saccharomyces cerevisiae. Eur J Biochem 220, 83-96.

Cabib, E., Roberts, R. \& Bowers, B. (1982). Synthesis of the yeast cell wall and its regulation. Annu Rev Biochem 51, 763-793.

Datta, A., Ganesan, K. \& Natarajan, K. (1989). Current trends in Candida albicans research. Adv Microb Physiol 30, 53-88.

Fonzi, W. A. \& Irwin, M. Y. (1993). Isogenic strain construction and gene mapping in Candida albicans. Genetics 134, 717-728.

Gehring, A. M., Lees, W. J., Mindiola, D. J., Walsh, C. T. \& Brown, E. D. (1996). Acetyltransfer precedes uridylyltransfer in the formation of UDP-N-acetylglucosamine in separable active sites of the bifunctional GlmU protein of Escherichia coli. Biochemistry 35, 579-585.

Gopal, P., Sullivan, P. A. \& Shepherd, M. G. (1982). Enzymes of Nacetylglucosamine metabolism during germ-tube formation in Candida albicans. J Gen Microbiol 128, 2319-2326.

Gow, N. A. R. \& Gooday, G. W. (1987). Cytological aspects of dimorphism in Candida albicans. Crit Rev Microbiol 15, 73-78.

Herscovics, A. \& Orlean, P. (1993). Glycoprotein biosynthesis in yeast. FASEB J 7, 540-550.

Hofmann, M., Boles, E. \& Zimmermann, F. K. (1994). Characterization of the essential yeast gene encoding $N$-acetylglucosamine-phosphate mutase. Eur J Biochem 221, 741-747.

Holtje, J. V. \& Schwartz, U. (1985). Molecular Cytology of Escherichia coli, pp. 77-119. Edited by N. Nanninga. New York: Academic Press.

Ito, H., Fukuda, Y., Murata, K. \& Kimura, A. (1983). Transformation of intact yeast cells treated with alkali cations. $J$ Bacteriol 153, 163-168.

Kasahara, S., Yamada, H., Mio, T., Shiratori, Y., Miyamoto, C., Yabe, T., Nakajima, T., Ichishima, E. \& Furuichi, Y. (1994). Cloning of the Saccharomyces cerevisiae gene whose overexpression overcomes the effects of HM-1 killer toxin, which inhibits $\beta$ glucan synthesis. J. Bacteriol 176, 1488-1499.
Lundblad, V. (1992). Saccharomyces cerevisiae. In Current Protocols in Molecular Biology, pp. 13.1-13.13. Edited by F. M. Ausubel, R. Brent, R. E. Kingston, D. D. Moore, J. G. Seidman, J. A. Smith \& K. Struhl. New York: Wiley Interscience.

Mio, T., Yabe, T., Arisawa, M. \& Yamada-Okabe, H. (1998). The eukaryotic UDP-N-acetylglucosamine pyrophosphorylases. Gene cloning, protein expression, and catalytic mechanism. J Biol Chem 273, 14392-14397.

Mio, T., Yamada-Okabe, T., Arisawa, M. \& Yamada-Okabe, H. (1999). Saccharomyces cerevisiae GNA1, an essential gene encoding a novel acetyltransferase involved in UDP- $N$-acetylglucosamine synthesis. J Biol Chem 274, 424-429.

Odds, F. C. (1987). Candida infection: an overview. Crit Rev Microbiol 15, 1-5.

Odds, F. C. (1994). Candida species and virulence. ASM News 60, 313-318.

Park, J. T. (1987). Escherichia coli and Salmonella typhimurinum: Cellular and Molecular Biology, pp. 663-671. Edited by F. C. Neidhardt and others. Washington, DC: American Society for Microbiology.

Raetz, C. R. H. (1987). Escherichia coli and Salmonella typhimurinum: Cellular and Molecular Biology, pp. 498-503. Edited by F. C. Neidhardt and others. Washington, DC: American Society for Microbiology.

Riddles, P. W., Blakeley, R. L. \& Zerner, B. (1983). Reassessment of Ellman's reagent. Methods Enzymol 91, 49-60.

Shepherd, M. G. (1985). Candida albicans: biology, genetics, and pathogenicity. Annu Rev Microbiol 39, 579-614.

Singh, B. \& Datta, A. (1979). Induction of $N$-acetylglucosaminecatabolic pathway in spheroplasts of Candida albicans. Biochem J 178, 427-431.

Smith, R. J., Milewski, S., Brown, A. J. \& Gooday, G. W. (1996). Isolation and characterization of the GFA1 gene encoding the glutamine:fructose-6-phosphate amidotransferase of Candida albicans. J Bacteriol 178, 2320-2327.

Watzele, G. \& Tanner, W. (1989). Cloning of the glutamine: fructose-6-phosphate amidotransferase gene from yeast. Pheromonal regulation of its transcription. J Biol Chem 264, 8753-8758.

Whelan, W. L. \& Ballou, C. E. (1975). Sporulation in D-glucosamine auxotrophs of Saccharomyces cerevisiae: meiosis with defective ascospore wall formation. J Bacteriol 125, 1545-1557.

Yamada-Okabe, T., Shimmi, O., Doi, R., Mizumoto, K., Arisawa, M. \& Yamada-Okabe, H. (1996). Isolation of the mRNA-capping enzyme and ferric-reductase-related genes from Candida albicans. Microbiology 142, 2515-2523.

Received 20 December 1999; revised 2 March 2000; accepted 16 March 2000. 